\title{
Effects of clonidine and some $a$-adrenergic antagonists alone and in combination on schedule-controlled behavior in pigeons and mice
}

\author{
Jonathan L. Katz \\ Harvard Medical School and University of Michigan Medical School
}

\begin{abstract}
Schedule-controlled responding was maintained under multiple fixed-interval, fixed-ratio schedules in pigeons and single fixed-ratio schedules in mice. In pigeons, clonidine, an $\alpha_{2}$-receptor agonist, produced dose-related decreases in responding under both fixed-interval and fixedratio schedules; fixed-interval responding was decreased at a lower dose than fixed-ratio responding. Low to intermediate doses of yohimbine, an $\alpha_{2}$-receptor antagonist, increased responding under the fixed-interval schedule without appreciably affecting responding under the fixed-ratio schedule; higher doses decreased responding under both schedules. In mice, both clonidine and yohimbine produced dose-related decreases in responding under fixed-ratio schedules. Decreases in response rates produced by clonidine were antagonized by low to intermediate doses of yohimbine. Decreases in response rates under fixed-ratio schedules produced by yohimbine were antagonized only slightly, if at all, by clonidine. Under the fixed-interval schedule, clonidine potentiated the response-rate increasing effects of intermediate doses of yohimbine and slightly antagonized the rate-decreasing effects. Although some effects of clonidine were antagonized by yohimbine, at no dose combination did performances completely resemble control performances. Prazosin, an $\alpha_{1}$-receptor antagonist, was ineffective both when administered alone and as an antagonist of the effects of clonidine. The behavioral effects of clonidine appeared to be mediated by $\alpha_{2}$ rather than $\alpha_{1}$ receptors. Additionally, yohimbine appears to have significant behavioral effects other than $\alpha_{2}$-antagonist actions.
\end{abstract}

Key words: Clonidine - Yohimbine - Prazosin - $\alpha$-Adrenergic agents - Schedule-controlled behavior - Pigeons Mice

Clonidine is a potent $\alpha$-adrenoreceptor agonist, which is thought to act primarily on the $\alpha_{2}$-subclass of adrenergic receptors (Starke and Altmann 1973). Behavioral studies have found that locomotor activity (Laverty 1969) and conditioned avoidance responding (Laverty 1969; Delbarre and Schmitt 1974) are decreased by clonidine, and that clonidine has analgesic effects that are not antagonized by naloxone (Paalzow and Paalzow 1976). Schedule-controlled responding maintained by food reinforcement is decreased

Offprint requests to: Jonathan L. Katz, NIDA Addiction Research Center, P.O. Box 5180, Baltimore, MD 21224, USA by clonidine in a dose-related manner when either low rates (Tilson et al. 1977) or high rates (McCleary and Leander 1981) of responding are maintained.

Studies of antagonism of the behavioral effects of clonidine have found yohimbine, piperoxan, and phentolamine to be effective antagonists of analgesia (Paalzow and Paalzow 1976) and decrements in locomotor activity (Delini-Stula et al. 1979; Nomura et al. 1980) produced by clonidine. Decreases in intracranial self-stimulation (Franklin and Herberg 1977) or avoidance responding (Robson et al. 1978) produced by clonidine are antagonized by piperoxan but not, however, by phentolamine. Because yohimbine and piperoxan are relatively selective antagonists of $\alpha_{2}$-receptors (Starke et al. 1975a; Borowski et al. 1977), the behavioral effects of clonidine may be due primarily to an agonist action at $\alpha_{2}$-receptors. Mixed results with phentolamine as an antagonist of clonidine are not easily explained. As with the other antagonists, phentolamine has antagonist actions at both $\alpha_{1}$ - and $\alpha_{2}$-receptors (Borowski et al. 1977; U'Prichard et al. 1978). Which action of phentolamine predominates at low concentrations has been inconsistent in studies employing different preparations (e.g., Borowski et al. 1977; Cubeddu et al. 1974).

The present studies were designed to explore further the behavioral effects of clonidine and its interaction with specific $\alpha$-adrenoreceptor antagonists. Pigeons and mice were trained to respond under multiple fixed-interval, fixed-ratio, or single fixed-ratio schedules, respectively. Effects of clonidine, yohimbine, and the selective $\alpha_{2}$-receptor antagonist, prazosin (Doxey et al. 1977; U'Prichard et al. 1978), were studied alone, and each antagonist was studied in combination with clonidine.

\section{Materials and Methods}

Subjects. Six mature White Carneaux pigeons (Columba livia) weighing $400-504 \mathrm{~g}$, and five adult male CD-1 and four adult male Swiss-Webster mice weighing 24 to $28 \mathrm{~g}$ were used. Between experimental sessions, subjects were housed in individual home cages and had unrestricted access to water and grit (pigeons). Subjects were maintained at $80 \%$ of their unrestricted-feeding weights by limiting post session access to mixed grain (pigeons) or P. J. Noyes food pellets (mice). Three pigeons had been used previously in other studies and were used here for studies of clonidine effects alone. The other three pigeons and the mice were experimentally naive at the beginning of these studies. 
Apparatus. During experimental sessions, pigeons were placed in a chamber similar to one described by Ferster and Skinner (1957). The chamber was ventilated and supplied continuously with white masking noise. Centered on the front panel of the chamber, $19 \mathrm{~cm}$ above the wire-mesh floor, was a translucent response key (R. Gerbrands Co., Model B). A horizontal force on the key of $15 \mathrm{~g}(0.15 \mathrm{~N})$ produced a feedback click and was recorded as a response. Three pairs of colored lamps $(7.5 \mathrm{~W}, 120 \mathrm{~V}, \mathrm{ac})$ could transilluminate the response key and serve as stimuli. Centered $4 \mathrm{~cm}$ above the floor on the front panel was a $4.5 \times 5.0 \mathrm{~cm}$ opening through which food (4-sec access to mixed grain) could be made available by a solenoid-driven tray ( $R$. Gerbrands Co., Model B). During food availability the aperture was illuminated by two lamps $(6 \mathrm{~W}, 120 \mathrm{~V}, \mathrm{ac})$ and stimulus lights were out.

During experimental sessions, mice were placed in a Plexiglas chamber modified from one described by Wenger and Dews (1976). The chamber was placed in a ventilated, sound-attenuating enclosure. In the front of the chamber was a small corridor that had a metal floor and was closed at the far end. Protruding through the wall at the end of the corridor was a BRS/LVE small-rodent response paddle (model RLP-003). This paddle was connected on the other side of the wall to the housing for a BRS/LVE rat lever (model CRL-005) with microswitch and counterweights removed. On the side of the fulcrum of the lever away from the mouse was mounted a shutter. When the mouse depressed the lever, the shutter interrupted a light beam directed to a photocell. Interruption of the beam counted as a response. Weight was added to the lever so that a minimal downward force of $2 \mathrm{~g}$ was necessary to count as a response. Each response produced an audible feedback click. An overhead white lamp $(7.5 \mathrm{~W}, 120 \mathrm{~V}$, ac $)$ could be illuminated and serve as a visual stimulus. White noise, provided through a speaker mounted on the back wall directly opposite the corridor, could be used as an auditory stimulus. A solenoid-operated dipper (R. Gerbrands, model B-LH) could deliver $0.025 \mathrm{ml}$ evaporated milk through an aperture in the floor of the corridor.

Procedure. Pigeons were trained to peck the response key during daily experimental sessions that were conducted 5 days/week. During sessions key-peck responses produced food according to a multiple fixed-interval, fixed-ratio schedule. When the key was green, the first response after $10 \mathrm{~min}$ had elapsed produced food (10-min fixed-interval schedule). When the key was blue, the 30th response produced food (30-response fixed-ratio schedule). Fixedinterval and fixed-ratio components of the multiple schedule alternated with each food presentation. Components alternated without food delivery if a response did not produce food within $1 \mathrm{~min}$ after the lapse of the 10-min fixed interval or if 30 responses were not emitted within $1 \mathrm{~min}$ in the fixed-ratio component. Sessions started with the fixed-interval component and ended after the 12th fixedratio component (about $2 \mathrm{~h}$ ).

Mice were trained to depress the response lever during daily experimental sessions conducted 5 days/week. During sessions lever-press responses produced food according to a 30-response fixed-ratio schedule. When the overhead light and white noise were on, each 30th response produced 3-s access to the milk-filled dipper. Sessions started with a 15min period during which the light and white noise were off and responding had no scheduled consequences. At the end of that period, the light and white noise were turned on, and the session lasted until food had been presented 50 times or until $15 \mathrm{~min}$ had elapsed.

Drugs. Once performances were stable from day to day, effects of drugs were studied. Drugs were administered immediately before selected sessions and no more frequently than once every 3 days (typically Tuesdays and Fridays). Drugs were administered IM (pectoral muscle) in pigeons, typically in a volume of $1 \mathrm{ml} / \mathrm{kg}$, and IP in mice, typically in a volume of $1 \mathrm{ml} / 0.1 \mathrm{~kg}$. The highest dose of prazosin was administered at twice the usual volume. Clonidine $\mathrm{HCl}$ (Boehringer Ingelheim, FRG) and yohimbine $\mathrm{HCl}$ (Sigma Chemicals, St. Louis, MO, USA) were dissolved in $0.9 \%$ $\mathrm{NaCl}$ for injection. Prazosin $\mathrm{HCl}$ (Pfizer, Groton, CT, USA) was dissolved in distilled water with warming. Doses are expressed as $\mathrm{mg} / \mathrm{kg}$ of the salt. Complete dose-effect functions were typically studied with one drug before beginning studies with the next, and each dose was typically studied twice in each subject.

\section{Results}

Effects of drugs alone. Average response rates in pigeons were decreased in a dose-related manner by clonidine (Fig. 1). Responding under the fixed-interval schedule was decreaased at a dose one-half log unit lower than the dose necessary to decrease responding under the fixed-ratio schedule. Performances after clonidine $(0.03 \mathrm{mg} / \mathrm{kg})$ are compared to control performances in Fig. 2. At that dose there was a substantial decrease in fixed-interval responding and a disruption in the typical pattern of positive acceleration in responding within the interval. Responding after clonidine occurred earlier in the interval, did not typically accelerate to as high a rate and often was interrupted. In contrast, fixed-ratio responding was affected less.

Clonidine also decreased fixed-ratio responding in mice (Fig. 1). Doses up to $0.01 \mathrm{mg} / \mathrm{kg}$ were ineffective, whereas higher doses produced dose-dependent decrease in responding.

In pigeons, low to intermediate doses of yohimbine $(0.01-0.1 \mathrm{mg} / \mathrm{kg})$ increased response rates under the fixedinterval schedule without producing substantial changes in responding under the fixed-ratio schedule (Fig. 1). Compared to control performances, there were shorter pauses and higher response rates in the early portions of the fixed interval, whereas responding under the fixed-ratio schedule was not appreciably affected (data not shown). Higher doses $(0.3-1.0 \mathrm{mg} / \mathrm{kg})$ decreased responding under both schedules (Fig. 1).

Yohimbine also fixed-ratio responding in mice (Fig. 1). Doses $1.0-17.0 \mathrm{mg} / \mathrm{kg}$ produced dose-dependent decreases in responding. Yohimbine was about 10 times more potent in decreasing fixed-ratio responding in pigeons than in mice.

Prazosin $(0.01-1.0 \mathrm{mg} / \mathrm{kg})$ did not affect responding under either the fixed-interval or fixed-ratio schedules. A higher dose $(10.0 \mathrm{mg} / \mathrm{kg})$ decreased rates to about $60 \%$ $-70 \%$ of control values (Table 1 ).

Effects of drugs in combination. Effects of combinations of clonidine and yohimbine in pigeons were complex and dose dependent. Yohimbine at low to intermediate doses $(0.003-0.1 \mathrm{mg} / \mathrm{kg})$ antagonized the decreases in response 


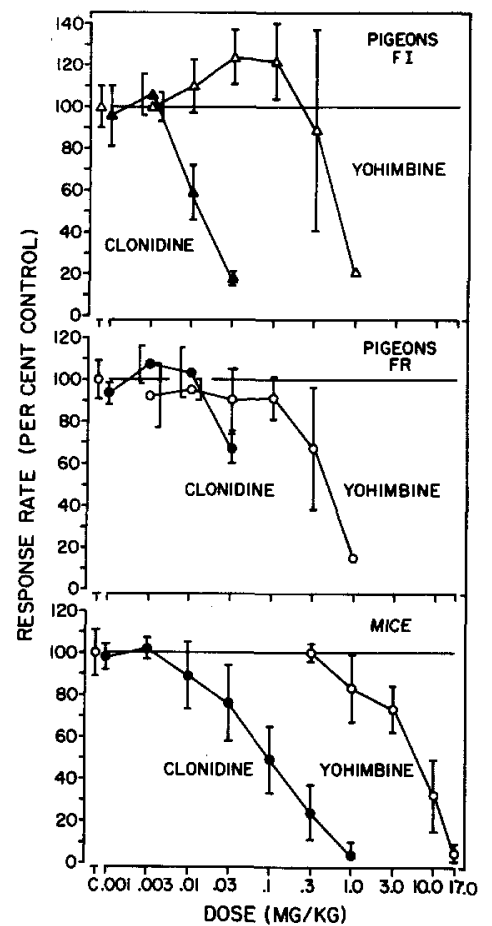

Fig. 1. Effects of clonidine and yohimbine on rates of responding under the multiple fixed-interval, fixed-ratio schedule in pigeons and under the fixed-ratio schedule in mice. Abscissae: dose, log scale; ordinates: response rates expressed as a percentage of rates during control sessions. Filled symbols represent effects of clonidine; open symbols represent effects of yohimbine. Triangles represent rates of responding under the fixed-interval schedule; circles represent rates of responding under the fixed-ratio schedule. Average control rates of responding were, for pigeons, 0.53 and 2.34 responses per second under the fixedinterval and fixed-ratio schedules, respectively, and 3.11 responses per second for mice. Vertical lines about the points represent \pm 1 SD of the means. If lines are not present, the point encompasses the SD. Each point for clonidine is the mean of two observations in each of six pigeons or nine mice. Each point for yohimbine is the mean of two observations in each of three pigeons or seven mice. Note that clonidine decreased responding in pigeons under the fixed-interval schedule at a dose about one-half log unit lower than that producing a comparable decrease in responding under the fixed-ratio schedule. Also note that yohimbine increased responding in pigeons under the fixed-interval schedule at doses that did not appreciably affect responding under the fixed-ratio schedule

rates produced by $0.03 \mathrm{mg} / \mathrm{kg}$ clonidine (Fig. 3). At a dose of $0.03 \mathrm{mg} / \mathrm{kg}$ of yohimbine, average response rates closely approximated control values. Although the average rates of responding after the drug combination were comparable to control response rates, patterns of responding were characterized by shorter pauses and higher response rates early in the interval (Fig. 2). At no dose combination did yohimbine restore the temporal pattern of responding such that it resembled control performance.

The decreases in response rates produced by yohimbine $(0.3-1.0 \mathrm{mg} / \mathrm{kg})$ were antagonized to some extent by clonidine (Fig. 3). Under the fixed-interval schedule, the rate-decreasing effects of yohimbine were shifted about onehalf $\log$ unit to the right. The rate-decreasing effects of yohimbine $(0.3 \mathrm{mg} / \mathrm{kg})$ under the fixed-ratio schedule were antagonized only marginally, if at all, by clonidine.

At certain dose combinations $(0.03 \mathrm{mg} / \mathrm{kg}$ clonidine with 0.1 to $1.0 \mathrm{mg} / \mathrm{kg}$ yohimbine), rates of responding within the fixed interval were increased to values above those produced by yohimbine alone (Fig. 3). For example, after yohimbine $(0.1 \mathrm{mg} / \mathrm{mg})$ and clonidine $(0.03 \mathrm{mg} / \mathrm{kg})$, pauses under the fixed-interval schedule were shortened (especially later in the session) and average response rates were much greater than control values and greater than those after yohimbine alone (Fig. 3).

In mice, decreases in fixed-ratio response rates produced by clonidine were also antagonized by yohimbine. Doses of yohimbine (1.0 and $3.0 \mathrm{mg} / \mathrm{kg}$ ) partly antagonized the effects of clonidine $(0.3 \mathrm{mg} / \mathrm{kg}$; Fig. 4). In two subjects the rates were closest to control values at $1.0 \mathrm{mg} / \mathrm{kg}$ and the other two at $3.0 \mathrm{mg} / \mathrm{kg}$ of yohimbine; however, in no subject did the response rates after drug combinations reach control levels. The maximal rate in individual subjects after these drug combinations was $72.8 \%-78.7 \%$ of control.

Decreases in fixed-ratio response rates in mice produced by yohimbine were only marginally, if at all, antagonized by clonidine (Fig. 5); the antagonism of the decrease in response rate was modest and always less than the antagonism of effects of clonidine by yohimbine. The maximal response rate in individual subjects after combinations of clonidine with a rate-decreasing dose of yohimbine ranged from $46.5 \%$ to $56.3 \%$ of control.

Prazosin, in doses of $0.01-10.0 \mathrm{mg} / \mathrm{kg}$, did not antagonize the decreases in response rates produced by clonidine (Table 1) under either the fixed-interval or fixedratio schedule in pigeons.

\section{Discussion}

In the present studies, clonidine decreased responding under both fixed-interval and fixed-ratio schedules; however, decreases in responding occurred at doses approximately one-half $\log$ unit lower under the fixed-interval schedule. These results are similar to those reported previously for effects on schedule-controlled behavior of the adrenergic agonists epinephrine in pigeons (Wurtman et al. 1959) and $\alpha$-methylnorepinephrine in chicks (Marley and Morse 1967).

The norepinephrine-depleting drugs, reserpine (Smith 1964) and tetrabenazine (McMillan 1968a), also decrease responding under fixed-interval schedules while producing less of an effect on responding under fixed-ratio schedules. A common mechanism by which norepinephrine-depleting compounds and adrenoreceptor agonists might have similar effects is by functionally reducing the amount of transmitter available at postsynaptic receptors. Adrenergic agonists might do so by acting at inhibitory presynaptic receptors, thereby limiting the release of norepinephrine. All three adrenergic agonists, clonidine, $\alpha$-methylnorepinephrine and epinephrine, that decrease fixed-interval responding at doses lower than those that decrease fixed-ratio responding have greater potencies at presynaptic than postsynaptic $\alpha$ receptors (Starke et al. 1975b).

In contrast to the present effects of clonidine, other sympathomimetic amines, such as $d$-amphetamine, mephentermine, and ephedrine, increase responding under fixed-interval schedules at doses that do not appreciably affect responding under fixed-ratio schedules (McMillan 1968 b). Other sympathomimetic agonists such as norepinephrine, phenylephrine (McMillan 1968 b) or tyramine (Carney 1977) decrease responding under both fixed-interval and fixed-ratio schedules at the same dose. These agonists 


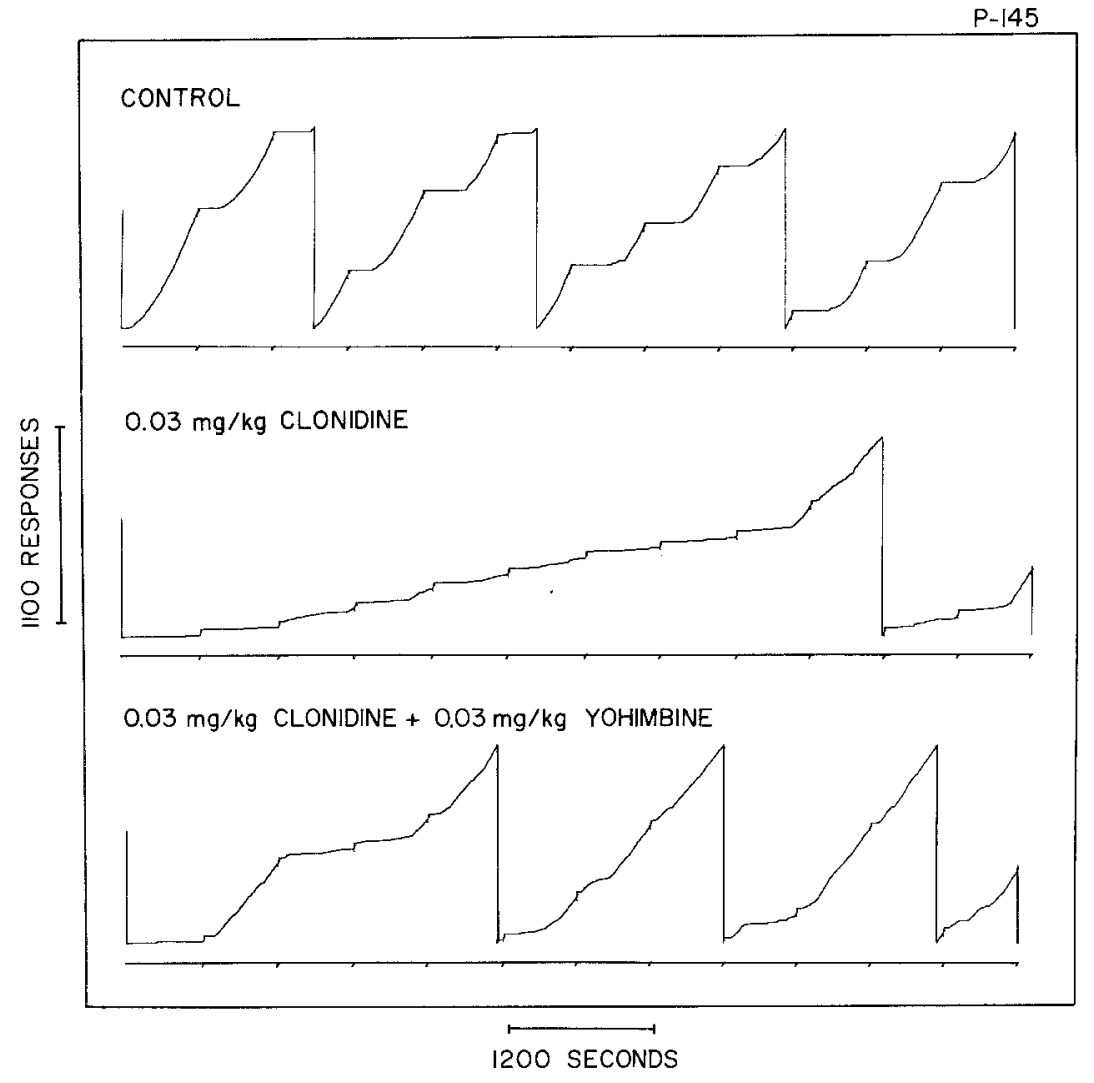

Fig. 2

Representative control performance of pigeon P-145 under the multiple fixed-interval, fixedratio schedule and effects of clonidine $(0.03 \mathrm{mg} /$ $\mathrm{kg}$ ) alone and in combination with yohimbine $(0.03 \mathrm{mg} / \mathrm{kg})$. Abscissae: time; ordinates: cumulative number of key-peck responses. The fixedinterval and fixed-ratio components alternated and fixed-ratio components are indicated by a downward displacement of the lower horizontal event lines. Diagonal strokes on the cumulative response curve indicate food presentations. The cumulative response curve reset to base after 1100 responses. Note the decreases in responding under the fixed-interval schedule without large changes in responding under the fixed-ratio schedule. Note also that yohimbine antagonized the overall decreases in response rates produced by clonidine but that patterns of responding after the two drugs in combination did not resemble control patterns of responding

Table 1. Effects of prazosin when administered alone and in combination with clonidine $(0.03 \mathrm{mg} / \mathrm{kg})$ (percent of control response rate)

\begin{tabular}{lrrrrr}
\hline \multirow{2}{*}{ Dose $(\mathrm{mg} / \mathrm{kg})$} & \multicolumn{2}{l}{ Prazosin alone } & & \multicolumn{2}{l}{ Prazosin with clonidine } \\
\cline { 2 - 3 } \cline { 5 - 6 } & FI & FR & & FI & FR \\
\hline- & & & 21.7 & 44.1 \\
0.01 & 75.6 & 91.5 & 10.9 & 33.0 \\
0.1 & 109.5 & 107.2 & 13.0 & 14.5 \\
0.3 & 117.1 & 103.7 & 13.0 & 33.9 \\
1.0 & 96.9 & 94.2 & 10.9 & 43.2 \\
3.0 & 70.1 & 57.5 & 8.7 & 20.3 \\
10.0 & & & & \\
\hline
\end{tabular}

act primarily on postsynaptic receptors either by direct or indirect actions (Trendelenburg et al. 1962).

Yohimbine increased responding under the fixed-interval schedule at doses that had little effect on responding under the fixed-ratio schedule. Higher doses decreased responding under both schedules. These effects of yohimbine are qualitatively similar to effects of $d$-amphetamine on schedule-controlled performances of pigeons (Smith 1964; McMillan 1968b; Katz 1982). Other behavioral effects of yohimbine, however, differ from those of $d$-amphetamine. For example, yohimbine generally decreases locomotor activity in mice (Sanghvi and Gershon 1974), whereas $d$ amphetamine can increase locomotor activity (Van Rossum et al. 1962; Smith 1963). Additionally, yohimbine has been reported to increase rates of responding suppressed by punishment (Sethy and Winter 1972), where as $d$-amphetamine typically only decreases rates of punished responding (Geller

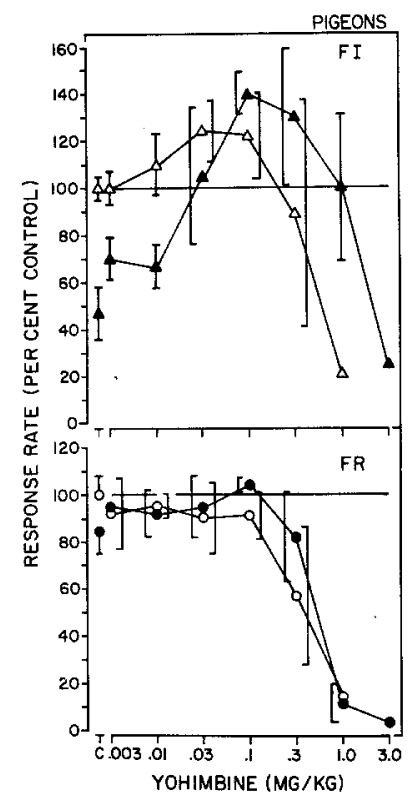

Fig. 3. Effects of yohimbine alone and combinations of yohimbine and clonidine on rates of responding under a multiple fixed-interval, fixedratio schedule in pigeons. Coordinates and symbols are as in Fig. 1. Vertical lines about open points above $\mathrm{C}$ represent $\pm 1 \mathrm{SD}$ of the means of control observations. Filled points above $\mathrm{C}$ represent response rates after $0.03 \mathrm{mg} / \mathrm{kg}$ clonidine. Open points above doses represent effects of yohimbine alone (as in Fig. 1). Filled points above doses represent effects of yohimbine in combination with clonidine $(0.03 \mathrm{mg} / \mathrm{kg})$. Each of these points is typically the mean of at least two observations at each dose in three subjects. Note that low to intermediate doses of yohimbine antagonized the decreases in response rates produced by clonidine and that clonidine antagonized the decreases in response rates produced by yohimbine, most notably in the fixed-interval component. Finally, clonidine potentiated the increases in response rates produced by yohimbine 


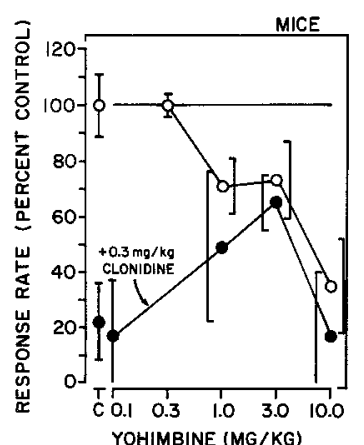

Fig. 4. Effects of yohimbine on decreases in response rates produced by clonidine in mice responding under a fixed-ratio schedule. Vertical lines about the open point above $\mathrm{C}$ represent $\pm 1 \mathrm{SD}$ of the mean of control observations. The closed point above $\mathrm{C}$ represents the mean of observations of effects of clonidine $(0.3 \mathrm{mg} / \mathrm{kg})$. Filled points above yohimbine doses represent effects of yohimbine in combination with clonidine $(0.3 \mathrm{mg} / \mathrm{kg})$. Each of these points is typically the mean of at least two observations at each dose in each of four subjects. Open points represent mean effects of yohimbine alone in these four subjects. Note that yohimbine antagonized, in a dose-dependent manner, the decrease in response rates produced by clonidine

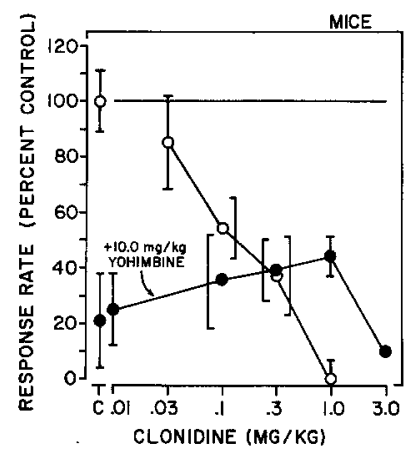

Fig. 5. Effects of clonidine on decreases in response rate produced by yohimbine in mice responding under the fixed-ratio schedule. Vertical lines about the open point above $C$ represent \pm 1 SD of the mean of control observations. The closed point above $\mathrm{C}$ represents the mean of observations of effects of yohimbine $(10.0 \mathrm{mg} / \mathrm{kg})$. Filled points above clonidine doses represent effects of clonidine in combination with yohimbine $(10.0 \mathrm{mg} / \mathrm{kg})$. Each of these points is typically the mean of at least two observations at each dose in each of three subjects. Open points above clonidine doses represent mean effects of clonidine alone in these three subjects. Note that clonidine only marginally antagonized the response rate decreases produced by yohimbine

and Seifter 1960). Thus, yohimbine has a unique spectrum of behavioral effects and warrants further study.

The interaction in pigeons of a large dose of clonidine with yohimbine was complex. The response-rate decreasing effects of clonidine were antagonized by low to intermediate doses of yohimbine. Conversely, the decreases in response rates under the fixed-interval schedule produced by yohimbine were antagonized by clonidine. The antagonism of effects of yohimbine by clonidine under fixed-ratio schedules, however, was slight. In mice the antagonism of effects of yohimbine by clonidine was marginal and less than the antagonism of clonidine by yohimbine. The antagonism of yohimbine by clonidine may have been limited by the response-rate decreasing effects of clonidine; doses of clonidine that partly antagonized effects of yohimbine decreased response rates when administered alone. In pigeons, however, the dose of clonidine that was studied in combination with yohimbine only slightly decreased responding under the fixed-ratio schedule. Thus, the effects of clonidine alone do not fully account for the lack of a robust antagonism of effects of yohimbine by clonidine.

Vaillant (1964) suggested that a specific antagonism of the behavioral effects of an agonist is strongly indicated if a complex performance disrupted by the agonist is restored to control in all important aspects. Such was the case with combinations of physostigmine and atropine (Vaillant 1964). A similar restoration of control performances disrupted by morphine has been achieved by administering the pure opioid antagonist, naloxone (Byrd 1976; McMillan et al. 1970); in contrast, nonspecific antagonism of effects of morphine was obtained with $d$-amphetamine (Byrd 1976; McMillan et al. 1970). Recently, Witkin et al. (1983) have replicated the specific antagonism of morphine by naloxone and additionally shown that meperidine has nonopioid behavioral effects when studied in combination with naloxone. Following and extending interpretations of these previous results, if rates but not patterns of responding are similar to control following drug combinations, the antagonism is either nonspecific (physiological), the agonist has more than one action of which only one is antagonized, or the antagonist has actions in addition to its antagonist effects.

In the present study, combinations of clonidine and yohimbine that restored average response rates to control levels did not restore the patterns of responding to those seen when no drugs were administered. Since there is ample evidence that clonidine and yohimbine have agonist and antagonist actions, respectively, at $\alpha_{2}$-receptors (Starke 1977), it is unlikely that the present interactions are merely physiological. Clonidine also has affinity for $\alpha_{1}$-receptors (Starke et al. 1975a) and releases histamine (Kenakin and Angus 1981); however, each of these actions occur at concentrations above those at which clonidine has $\alpha_{2}$-agonist actions. Since yohimbine increased response rates under the fixed-interval schedule when administered alone and clonidine potentiated those effects, it appears that the rateincreasing effects of yohimbine are due to some action other than $\alpha_{2}$-antagonist actions. Additionally, since clonidine only modestly reversed decreases in fixed-ratio responding produced by yohimbine, these effects of yohimbine might also be due to actions other than $\alpha_{2}$-antagonist actions. Thus, it appears that a significant portion of the behavioral activity of yohimbine is due to actions other than those at $\alpha_{2}$-adrenoreceptors, such as effects on serotonergic or dopaminergic systems (Papeschi et al. 1971; Scatton et al. 1980).

Prazosin, a relatively selective antagonist of $\alpha_{1^{-}}$ adrenoreceptors, did not antagonize the effects of clonidine across a wide range of doses up to a dose that decreased response rates when administered alone. Thus, the behavioral effects of clonidine appear to be mediated primarily by its actions at $\alpha_{2}$-adrenoreceptors.

Acknowledgements. These studies were initiated at the Harvard Medical School and were supported by USPHS Fellowship DA01505 and USPHS Grants DA-00499, MH-07658, MH-02094, DA02658 and $\mathrm{MH}-14275$. Completion of these studies at the University of Michigan Medical School was supported by USPHS Grant DA00254. Comments on an earlier version of the manuscript were kindly provided by Drs. J. E. Barrett, P. B. Dews, W. H. Morse, C. B. Smith, and R. D. Spealman. J. M. Witkin provided especially thoughtful discussions. Technical assistance was provided by James 
Holland, Catherine Jackson, Lionel King (HMS) and Fred M. Adams (UM). Ms. Kate Johnson and Ms. Troyce Holland provided assistance in preparation of the manuscript.

\section{References}

Borowski E, Starke K, Ehrl H, Endo T (1977) A comparison of pre- and postsynaptic effects of alpha-adrenolytic drugs in the pulmonary artery of the rabbit. Neuroscience $2: 285-296$

Byrd LD (1976) Effects of morphine alone and in combination with naloxone or $d$-amphetamine on shock-maintained behavior in the squirrel monkey. Psychopharmacology 49:225-234

Carney JM (1977) Pargyline-induced increases in sensitivity to the effects of drugs on operant behavior in pigeons. Psychopharmacology 52:97-102

Cubeddu L, Barnes EM, Langer SZ, Weiner N (1974) Release of norepinephrine and dopamine-beta-hydroxylase by nerve stimulation. I. Role of neuronal and extraneuronal uptake and of alpha presynaptic receptors. J Pharmacol Exp Ther $190: 431-450$

Delbarre B, Schmitt H (1974) Effects of clonidine and some alphaadrenoreceptor blocking agents on avoidance conditioned reflexes in rats: Their interactions and antagonism by atropine. Psychopharmacologia 35:195-202

Delini-Stula A, Baumann P, Buch O (1979) Depression of exploratory activity by clonidine in rats as a model for the detection of relative pre- and postsynaptic central noradrenergic receptor selectivity of alpha-adrenolytic drugs. Naunyn-Schmiedeberg's Arch Pharmacol 307:115-122

Doxey JC, Smith CFC, Walker JM (1977) Selectivity of blocking agents for pre- and postsynaptic alpha-adrenoreceptors. Br J Pharmacol 60:91-96

Ferster CB, Skinner BF (1957) Schedules of reinforcement. Appleton-Century-Crofts Inc, New York

Franklin KBJ, Herberg LJ (1977) Presynaptic alpha-adrenoreceptors: The depression of self-stimulation by clonidine and its restoration by piperoxane but not by phentolamine or phenoxybenzamine. Eur J Pharmacol 43:33-38

Geller I, Seifter J (1960) The effects of meprobamate, barbiturates, $d$-amphetamine and promazine on experimentally induced conflict in the rat. Psychopharmacologia 1:482-492

Katz JL (1982) Rate-dependent effect of $d$ - and $l$-amphetamine on schedule-controlled responding in pigeons and squirrel monkeys. Neuropharmacology $21: 235-242$

Kenakin TP, Angus JA (1981) The histamine-like effects of tolazoline and clonidine: Evidence against direct activity at histamine receptors. J Pharmacol Exp Ther 219:474-480

Laverty R (1969) A comparison of the behavioural effects of some hypotensive imidazoline derivatives in rats. Eur J Pharmacol $9: 163-169$

Marley E, Morse WH (1967) Effects of alpha-methyl derivatives of noradrenaline, phenethylamine and tryptamine on operant conditioning in chickens. Br J Pharmacol Chemother 31: $367-389$

McCleary PE, Leander JD (1981) Clonidine analgesia and suppression of operant responding: Dissociation of mechanism. Eur J Pharmacol 69:63-69

McMillan DE (1968a) Some interactions between sympathomimetic amines and amine-depleting agents on the schedule-controlled behavior of the pigeon and the squirrel monkey. I Pharmacol Exp Ther 163:172-187

McMillan DE (1968b) The effects of sympathomimetic amines on schedule-controlled behavior on the pigeon. J Pharmacol Exp Ther 160:315-325

McMillan DE, Morse WH (1967) Some effects of morphine and morphine antagonists on schedule-controlled behavior. J Pharmacol Exp Ther 157:175-184

McMillan DE, Wolf PS, Carcham RA (1970) Antagonism of behavioral effects of morphine and methadone by narcotic antagonists in the pigeon. J Pharmacol Exp Ther 175:443-458
Nomura Y, Oki K, Segawa T (1980) Pharmacological characterization of central alpha-adrenoreceptors which mediate clonidineinduced locomotor hypoactivity in the developing rat. NaunynSchmiedeberg's Arch Pharmacol 311:41 - 44

Paalzow G, Paalzow L (1976) Clonidine antinociceptive activity: Effects of drugs influencing central monoaminergic and cholinergic mechanisms in the rat. Naunyn-Schmiedeberg's Arch Pharmacol 292:119-126

Papeschi R, Sourkes TL, Youdim MBH (1971) The effect of yohimbine on brain serotonin metabolism, motor behavior and body temperature of the rat. Eur J Pharmacol 15:318 - 326

Robson RD, Antonaccio MJ, Saelens JK, Liebman J (1978) Antagonism by mianserin and classicial alpha-adrenoreceptor blocking drugs of some cardiovascular and behavioral effects of clonidine. Eur J Pharmacol 47:431 - 442

Sanghvi I, Gershon S (1974) Yohimbine: Behavioral and biochemical effects in mice. Arch Int Pharmacodyn Ther 210:108-120

Scatton B, Zivkovic B, Dedek J (1980) Antidopaminergic properties of yohimbine. J Pharmacol Exp Ther 215:494-499

Sethy VH, Winter JC (1972) Effects of yohimbine and mescaline on punished behavior in the rat. Psychopharmacologia $23: 160-166$

Smith CB (1963) Enhancement by reserpine and alpha-methyl dopa of the effects of $d$-amphetamine upon the locomotor activity of mice. J Pharmacol Exp Ther 142:343-350

Smith CB (1964) Effects of $d$-amphetamine upon operant behavior of pigeons: Enhancement by reserpine. J Pharmacol Exp Ther $146: 167-174$

Starke K (1977) Regulation of noradrenaline release by presynaptic receptor systems. Rev Physiol Biochem Pharmacol 77:1 - 124

Starke K, Altmann KP (1973) Inhibition of adrenergic neurotransmission by clonidine: An action on prejunctional alphareceptors. Neuropharmacology 12:339-347

Starke K, Borowski E, Endo T (1975a) Preferential blockade of presynaptic alpha-adrenoreceptors by yohimbine. Eur J Pharmacol 34:385-388

Starke K, Endo T, Taube HD (1975b) Relative pre- and postsynaptic potencies of alpha-adrenoreceptor agonists in the rabbit pulmonary artery. Naunyn-Schmiedeberg's Arch Pharmacol 291:55-78

Tilson HA, Chamberlain JH, Jonas AG, Buyniski JP (1977) Behavioral suppressant effects of clonidine in strains of normotensive and hypertensive rats. Eur J Pharmacol $43: 99-105$

Trendelenburg U, Muskus A, Fleming WW, De La Sierra BGA (1962) Modification by reserpine of the action of sympathomimetic amines in spinal cats; a classification of sympathomimetic amines. J Pharmacol Exp Ther 138:170 - 180

U'Prichard DC, Charness ME, Robertson D, Snyder SH (1978) Prazosin: Differential affinities for two populations of alphanoradrenergic receptor binding sites. Eur J Pharmacol 50: $87-89$

Vaillant GE (1964) Antagonism between physostigmine and atropine on the behavior of the pigeon. Naunyn-Schmiedeberg's Arch Exp Path Pharmakol 248:406-416

Van Rossum JM, Van der Schoot JB, Hurkmans JAThM (1962) Mechanism of action of cocaine and amphetamine in the brain. Experientia 18:229-231

Wenger GR, Dews PB (1976) The effects of phencyclidine, ketamine, $d$-amphetamine and pentobarbital on schedule-controlled behavior in the mouse. J Pharmacol Exp Ther 196:616-624

Witkin JM, Leander JD, Dykstra LA (1983) Modification of behavioral effects of morphine, meperidine, and normeperidine by naloxone and morphine tolerance. J Pharmacol Exp Ther $225: 275-283$

Wurtman RJ, Frank MM, Morse WH, Dews PB (1959) Studies on behavior. V. Actions of $l$-epinephrine and related compounds. J Pharmacol Exp Ther 127:281-287

Received March 29, 1983; Final version November 7, 1983 